\title{
LA PEDAGOGÍA DE CREACIÓN MUSICAL (PCM) Y SU DESARROLLO EN EL GRUPO DE CREACIÓN SONORA DE LA USC (GCSUS)
}

\author{
BUILDING THE MUSICAL PEDAGOGY AND ITS DEVELOPMENT IN THE \\ SOUND CREATION GROUP OF USC
}

\begin{abstract}
Una pedagogía de investigación y creación sonora con soportes en las músicas alternativas (electroacústica y arte sonora) y sus aplicaciones en la escuela ${ }^{1}$
\end{abstract}

A pedagogy research and sound creation with supports in alternative music (electro acoustic and sound art) and its applications in school

María Inmaculada Cárdenas Serván²

\section{RESUMEN}

Este artículo, a través de la presentación la trayectoria personal de la profesora e investigadora Inmaculada Cárdenas Serván presenta la evolución y el estado de la cuestión de la pedagogía de la creación musical, tanto en jóvenes universitarios, cuanto en niños de educación infantil. Casi tres décadas en la búsqueda de la mejor manera de transmitir la esencia de la música. Adquiriendo una nueva escucha dentro de las propuestas contemporáneas del arte sonoro y las propuestas musicales de otras culturas, a través de una actualización de la pedagogía de la música, adaptando esta a las nuevas tecnologías y los nuevos valores de la sociedad actual, que hoy se conoce como Pedagogía de la Creación Musical y que, recientemente, estaría más acorde empezar a denominarla Pedagogía de Creación Sonora.

\section{Palabras clave}

Pedagogía de la música, pedagogía de creación musical, música electroacústica, GRM (Groupe de Recherches Musicales), arte sonoro

\section{ABSTRACT}

This article, through the personal presentation of the teacher and researcher Immaculada Cárdenas Serván presents the evolution and the state of affairs of Pedagogy of Music Creation, in both university students, and in preschoolers. Nearly three decades in the search for the best way to convey the essence of music. Acquiring a new listener within contemporary art proposals sound and musical ideas of other cultures through an update of the teaching of music, adapting it to new technologies and new values of today's society, now called Pedagogy of Musical Creation and that recently would start calling it more in line Pedagogy of Resounding Creation.

\section{Keywords}

Pedagogy of Music, teaching music creation, electroacoustic music, GRM (Groupe de Recherches Musicales), sound art.

1 Lección Magistral ofrecida por las celebraciones del Día de Santo Tomas 2013 por la doctora Ma Inmaculada Cárdenas Serván de la Universidade de Santiango de Compostela (USC), Departamento de Historia del Arte, Escola de Maxisterio y Facultade de Xeografía e Historia.

2 Pianista titulada. Profesora de infantil. Historiadora por la Universidad de Sevilla. Doctora en Historia. Luthier. Especialista en pedagogía de la creación musical habiendo estudiado con François Delalande en París. Catedrática del Departamento de Historia del Arte de la USC. 
En este centro, hoy facultad, he desempeñado mi docencia e investigaciones desde el año 1983, y he dedicado todo mi esfuerzo para encontrar una pedagogía musical acorde con los tiempos que vivimos. Licenciada en historia por la Universidad de Sevilla y con los estudios superiores de piano en el Conservatorio de Música de la misma ciudad, recorríun espacio de mi vida como musicóloga, $y$ tuve el honor de ver mis descubrimientos publicados y expuestos en librerías musicales de Europa, me refiero a las seis sonatas para teclado de Manuel Blasco de Nebra, una joya del pre clasicismo español, dirigida por Miguel Querol director del Consejo Superior de Investigaciones Científicas (CSIC) y asesorada por Jacques Chailley director del Departamento de Musicología de La Sorbona, mi tesis de licenciatura sobre la vida musical de Sevilla en tiempos del polifonista Alonso Lobo, y la tesis doctoral sobre la música barroca andaluza en las colegiatas de Osuna y Olivares, serían las primeras tesis de musicología que se realizaron en universidades andaluzas en la década de los setenta. Un estudio posterior retomó partes de ambos trabajos, publicándose en la USC con el título de El Polifonista Alonso Lobo y su entorno. Mí llegada a esta universidad y el contacto con la pedagogía de la música cambiaría mi trayectoria profesional. La creación sonora y la pedagogía de la música ocuparían poco a poco todo mi tiempo hasta convertirse en el eje de mis investigaciones teóricas y prácticas hasta el presente.

Desde mis comienzos en esta universidad me pregunté sobre qué pedagogías serían más adecuadas para la formación de los maestros. Los métodos activos de pedagogía musical que se utilizaban en la década de los ochenta databan todos de finales del XIX y primera mitad del siglo XX y aunque sus logros de todos eran conocidos, no queríamos trabajar exclusivamente con métodos basados en los conceptos tonales, ya que no solucionaban temas como la falta de oído o de ritmo en los niños. Había que encontrar un método en el que lo tonal no fuera el centro. Trabajé $e$ investigué el folclore y la construcción de instrumentos antiguos en el taller de instrumentos populares de Vigo con Antón Corral realizamos una aproximación a flautas en PVC, en el taller de la Diputación de Lugo con Luciano Pérez sobre instrumentos de percusión gallegos. Organizamos un taller de construcción en este centro que funcionó algunos años. La técnica de construcción de instrumentos antiguos la había aprendido en Francia con el profesor Jean Temprement en la universidad de París VIII que vino a Lugo invitado por la universidad; pero los resultados no resolvían los problemas enunciados. No podemos achacarles nada, eran métodos anteriores a la grabadora y nuestra cultura transmitía la música a través de la escritura. Una cosa estaba clara, el ser humano no puede vivir sin arte, sin música, tenga esta la categoría que tenga y por ello, había que solucionar esta situación, ya que si la escuela no satisfacía la necesidad de experiencia musical de los niños, estos iban a buscarla fuera del aula. Leer a Ernest Fischer y su monografía La Necesidad del Arte es bastante elocuente sobre este tema.

Volví a Francia buscando una respuesta, François Delalande me recibió en el GRM. Corría el año 1986 y su libro La musique est un jeu d'enfant cambiaría mi manera de enfocar la música y la pedagogía de esta. $\mathrm{El}$ arte contemporáneo, las músicas alternativas y las músicas de otras culturas abrieron un espacio inusual y demasiado atractivo para alguien científicamente curioso. Todos los temas sin respuesta la encontraron como en un puzzle. La Música con mayúsculas dejaba paso al plural, las músicas, con toda la riqueza que esto implica.

Las teorías de Delalande tenían todas las respuestas que buscaba, y desde el 87 comienzo a trabajar en mis clases lo que luego denominaría en castellano la Pedagogía de Creación Musical (PCM) en mi monografía Evolución de la Pedagogía de la Música. Al siguiente año surge en las I Xornadas do Maxisterio Lucense, a las que estuvo invitado François Delalande, la posibilidad de trabajar con un grupo de artistas plásticos provenientes de la Escuela Ramón Falcón, como primer laboratorio de creación sonora. Nacía así El Grupo Espacio Permeable y el resultado después de cuatro años de trabajo fue el Concierto para Esculturas Sonoras que se estrenaba en Alicante en 1991 en el Festival de Música que organizó el compositor y amigo Llorenç Barber. En 2004 Juan Gil López realizaba un trabajo de investigación en el 
departamento de Musicología de Oviedo sobre este grupo. El Concierto para esculturas sonoras se programó en RNE, en Radio France, sonó en la sala Pradillo en Madrid, en el Teatro Principal de Santander, en el Museo de Esculturas Valladolid, e inauguró la Semana de Música del Corpus de Lugo de aquel año. Publicándose en el 1992 en CD por la fundación ACA en Mallorca. Había iniciado un camino sin retorno. En el 2002 este trabajo tenía una voz en el Diccionario Hispano Americano de Música publicado por la SGAE realizada por Ángel Medina de la universidad de Oviedo.

La Pedagogía de Creación Sonora PCM nacía con el nombre de Pedagogié de l'éveil en la década de los setenta en París (Francia) en el seno del $\mathrm{GRM}^{3}$ junto a maestras que se preguntaban si los juegos sonoros de los niños eran o no música. La nueva pedagogía musical tuvo el acierto de girar ciento ochenta grados la definición de música y abrirla a las músicas contemporáneas y a las músicas de otras culturas. El enfoque tradicional, basado en el conocimiento y práctica de los rudimentos de la música culta de occidente como único referente posible, incluido el folclore ya no era el único marco con el que trabajar.

Los planteamientos nuevos hay que entenderlos dentro del discurso de la música electroacústica francesa. Debíamos fijarnos en músicas con estructuras abiertas y sobre todo en las actitudes de los músicos cuando hacen música, estas son las mismas en todas las músicas del mundo. Era una de las claves para comprender el camino pedagógico que podíamos recorrer, junto a los objetivos de escuchar y producir sonidos, (incluido aprender a apreciar los ruidos), aprender a relacionar el sonido con las vivencias y buscar un sentido a la forma. El estudio del juego en Piaget aportó los tres niveles de trabajo que casaban con el desarrollo musical de una persona. Fue sorprendente constatar que todas las músicas tenían estos tres niveles de desarrollo: el juego senso motor, el juego simbolismo y el juego de reglas.

Los planteamientos de la PCM implican un cambio de mentalidad en el profesor de música, en los alumnos y por último en la sociedad. Si en el aula de música damos prioridad al juego sonoro, al "hacer" y no al "saber" y basamos el juego en la "escucha atenta" estamos proponiendo la invención y la creación sonora como camino y fin del currículo de trabajo en la escuela. Esto no es posible en la actualidad, porque los itinerarios curriculares no contemplan un marco flexible y abierto a propuestas sonoras experimentales, pero desde la universidad nuestra obligación es seguir trabajando en la búsqueda de las mejores propuestas pedagógicas para las aulas y transmitirlas a los futuros maestros. La realidad hoy es que muchos alumnos oyen con los ojos y no con los oídos. La banalización de la escucha es una realidad que nos habla de cómo utilizamos los oídos en nuestra sociedad.

La escucha la entendemos como una sensibilidad delicada y matizada que llamamos "escucha experta". Una persona que sabe escuchar, no solamente es una persona que disfruta más de la música, que es más musical, que sabe compartir su experiencia sonora con los demás, sino que sabe oír como los músicos y ver lo que estos ven en los sonidos. Músico es el que sabe escuchar, dice Llorenç Barber. Si aprender a escuchar es importante, aprender a escuchar desde la práctica sonora es enriquecedor y si esto se práctica en grupo es una vivencia educativa integradora. Si unimos estas metas tenemos la Pedagogía de Creación Musical, la PCM.

Formar maestros en pedagogía musical es educar sobre qué escuchamos y qué no. Pero pese a las realidades en la escuela con respecto a la educación musical, desde la universidad debemos incitar al conocimiento y desarrollo de pedagogías como la propuesta, porque va mucho más allá de abrir el marco educativo a las músicas contemporáneas, plantea un cambio de perspectiva en el significado de la escucha: ¿qué oímos? ¿qué escuchamos? y ¿qué comprendemos? tres niveles que cambian el lugar del oído en la educación.

No podemos educar marginando las otras músicas que son la mayoría de las músicas

GRM son las siglas del Groupe de Recherche Musicale del INA (Institut National de l'Audiovisuel). 
del mundo, máxime en una escuela diversa como la actual. Estas realidades sonoras, enriquecedoras en sí mismas, conllevan ejercitar la memoria sonora, pues todas ellas son ágrafas y se aprenden por repetición e imitación del maestro. Ellas poseen las polirritmias, los conceptos multiformes y las estructuras abiertas para entender sus realidades sonoras. Estos contextos los entendemos como atractivos para la escuela, enseñando el lado mágico de la música: jugar con el sonido en el sentido etimológico del término: aprehender el entorno, como hacen los pigmeos en los bosques africanos, una de las músicas más sugerentes y hermosas de África.

Las rupturas en educación no deben ser traumáticas y abrir la educación musical al conocimiento de estas músicas, debe hacerse jugando entre lo que somos y lo que podemos ser. Si la educación general comparte los dominios teóricos y los campos sensoriales, y estos últimos están en el arte, debemos comprender que enseñar prácticas musicales no puede ser teórico y por ello tenemos que cambiar la perspectiva. Cojamos por ejemplo la escritura de la música y planteemos ċqué es una partitura? un código para entender la música escrita. Pero podemos entender este código de forma abierta, y considerar como partitura todas aquellas formas que podamos inventar para retener lo que inventamos con el sonido.

Desde esta perspectiva la partitura más exacta, en el sentido literal del término sería la grabación de las improvisaciones sonoras. Me gusta pensar en ellas como una forma de partitura viva. Su exactitud no tiene comparación con ninguna otra anotación. La grabación nos permite retomar el trabajo sonoro en el punto en el que lo dejamos, con la misma energía y los matices en donde quedó. Pero cuando hablamos de partitura, también estamos hablando de la necesidad de retener parte del proceso de creación, de sus fases, y para ello podemos generar dibujos, pinturas, esquemas y signos que nos permitan recordar lo que estamos haciendo o queremos hacer, generando de esta forma partituras pictóricas, o simplemente escribir lo que queremos antes, o a partir de las grabaciones. Podemos plantear ejercicios pedagógicos en todas direcciones: pintar el sonido, sonar dibujos o sonar un texto o un poema, o sencillamente describir con palabras los sonidos. Los maravillosos adjetivos vendrán en nuestra ayuda. Podemos extender este trabajo al movimiento corporal puesto que la música parte del gesto y este siempre genera movimiento.

Lo que inventamos con el sonido es siempre complejo y cuando se trata de materias sonoras no podemos escribirlas con la grafía común. Las complicadas trayectorias sonoras que imagina un niño solo podremos dibujarlas, pintarlas o decirlas, porque estamos hablando desde otros parámetros musicales, que encontramos en músicas recientes como la "música hablada" del Trio Flatus Vocis, o los "paisajes sonoros" de Murray Shafer. Pero el gran marco sonoro desde el que trabajamos es el de la música electroacústica y concreta de Pierre Shaeffer que estudió los sonidos desde su naturaleza y los clasificó para trabajar la música desde un ámbito nunca antes imaginado hasta el trabajo del GRM en la década de los cincuenta del siglo XX.

Cuando se practica la PCM lo primero que queda claro es que todos los participantes del grupo tienen el mismo status. No hay nadie por encima en la toma de decisiones con respecto a la creación sonora. El debate y el análisis de los sonidos marcan la ruta de trabajo. El profesor conduce y guía al grupo y la responsabilidad se comparte entre todos. Las propuestas son consensuadas y el grupo camina cohesionado. El trabajo sonoro en grupo siempre es gratificante y la responsabilidad compartida equilibra las relaciones grupales. La sorpresa es mayúscula en relación a la respuesta de los niños cuando se les da poder de decisión o cuando se comparte las responsabilidades con ellos. Estos responden siempre positivamente y su percepción delicada de lo que quieren hacer con el sonido, siempre deja impresionado a los educadores ${ }^{4}$.

\footnotetext{
4 Un ejemplo de este tipo de trabajo es la propuesta de Música y Ciudad de Mónica Álvarez realizada con los alumnos del colegio público Montederramos de Ourense. Pueden escucharlo en www.rne.es en el podscat del programa La casa del sonido de José Luis Carles del 17 de junio de 2011.
} 
Hablamos desde nuestra experiencia a través de la cual hemos corroborado lo que decimos. Durante tres décadas hemos formado maestros y dirigido grupos de músicas experimentales. El primer grupo de música fue Espacio Permeable. El segundo grupo, actualmente en activo, es el grupo de música de la USC (Campus de Lugo) el GCMUS.

A lo largo de estas décadas hemos realizado talleres y cursos prácticos para la divulgación y conocimiento de esta pedagogía en Lugo y en otras universidades españolas y extranjeras y los resultados han sido siempre motivadores. En la práctica de la PCM hemos vivido desde la sorpresa inicial y el desconocimiento general de las propuestas por parte de los alumnos, a una participación activa de los mismos, con resultados brillantes en las concreciones de muchos grupos, obteniendo obras de calidad $y$ de gran profesionalidad. En estos cursos hemos establecido, como método de trabajo, el marco teórico, el conocimiento de las herramientas técnicas de base y su manejo, como la utilización de la grabadora, junto con el conocimiento básico de programas de ordenador, de descarga gratuita de la red, como Audacity o Reaper; y las propuestas prácticas enmarcadas dentro de la música concreta o electroacústica, que incluyen los sonidos urbanos o industriales del paisaje sonoro y las propuestas del arte sonoro como las que desarrolla Miguel Molina con sus alumnos de la Universitat Politécnica de Valencia invitado a los Sons Creativos en 2011 y 2012. Las propuestas sonoras son desarrolladas en grupos pequeños y el resultado participa de la "autoría compartida" como le gusta llamar a esta forma de trabajar al paisajista sonoro José Luis Carles.

En un aula que prácticala PCMlossaberestienden a democratizarse instintivamente, y por tanto, no estarán jerarquizados. La música no ocupará uno de los márgenes de los aprendizajes, y no será un adorno mal avenido con las expectativas sociales de los escolares y sus familias. Por el contrario, la práctica de la PCM se convertirá en una de las claves de la cohesión del grupo.
El maestro debe ser un guía del trabajo sonoro de los niños y el trabajo debe estar basado en compartir responsabilidades, trabajar la música desde propuestas compartidas y enfatizar en el "hacer" sonoro. El maestro que practica la Pedagogía de Creación Musical debe sentir como la presión en el aula se minimiza, y el vértigo de los alumnos por no estar a la altura de los compañeros, con los tradicionales problemas de falta de oído o de ritmo deja de ser un problema insalvable. El maestro también siente la mejora de las relaciones del grupo. La creación sonora ha de partir de propuestas elaboradas por este y compartidas por el mismo. A partir de aquí, la función del maestro se traslada de posición. De ser el eje que dirige los aprendizajes, se convierte en el dinamizador de estos.

Como dinamizador de las actividades musicales del grupo, el maestro estará encargado de propiciar que los grupos de trabajo que se formen en clase, tengan las herramientas necesarias para poder realizar las invenciones sonoras, esencialmente grabadoras, aparatos de reproducción, cámaras de fotos, y videos para la creación audiovisual. También disponer de otros dispositivos que dinamicen la invención, como la construcción de una biblioteca sonora y videoteca que sirva para la documentación, sin que olvidemos que esta la encontramos en Internet.

Las audiciones han ocupado en todas las pedagogías de la música, desde la invención del fonógrafo, un lugar destacado. En la Pedagogía de Creación Musical también las audiciones son un referente del trabajo a realizar por el grupo, si cabe aún mayor, pues a través de ellas surgirán ideas para la creación. La improvisación puede partir de una escucha concreta, una audición que se versiona por el grupo, o bien generarse a partir de una idea para la que se buscarán los elementos que irán desgranando el trabajo sonoro.

Las audiciones de músicas contemporáneas o extraeuropeas ${ }^{5}$ que tengan relación con

\footnotetext{
5 Quizás este término de músicas extraeuropeas no sea el más conveniente, puesto que hay ejemplos en el jazz, el rock, en músicas folclóricas europeas que también pueden ayudarnos en nuestro objetivo de aprender a escuchar de otra forma y apreciar otras propuestas, pero no queríamos utilizar el término de músicas no convencionales por parecernos aún más impreciso, por ello hemos optado por dejar músicas extraeuropeas entendiendo por ellas las que están fuera del marco de música culta de occidental.
} 
las propuestas que desarrollan los niños será uno de los trabajos de preparación de clases, determinante para el maestro que practica esta pedagogía. Su efecto en el grupo es de reforzar la sensación de estar haciendo, entre todos, algo bien. Estas audiciones de obras contemporáneas o extraeuropeas tienen la doble función de comparar lo que ellos hacen, con lo que hacen los profesionales de la música $y$ ver que hay relaciones y resemblanzas muy interesantes. Las audiciones son pieza fundamental de la PCM porque a través de ellas se amplia el horizonte sonoro de los niños y del maestro. No debemos olvidar que la creación sonora tiene en su origen la imitación y por tanto, estas audiciones abrirán nuevas perspectivas y alimentarán las propuestas de los escolares y del propio profesor.

Muchos artistas del siglo XX hablaron de la necesidad de volver a los orígenes en el arte, como algo necesario para que la sociedad encontrara de nuevo el pulso vital del arte y saliera del impasse en el que el arte del XIX había conducido a la sociedad. Muchos artistas evidenciaron con sus propuestas, durante el siglo pasado, que el arte puede ser de todos, como Duchamps; que era posible desmontar la "divinización" que en el siglo XIX se incrementó con los artistas. Devolver el arte y la música a "todos" era un sentimiento que estuvo en el aire durante la primera mitad del siglo pasado, los dadaístas lo concretizaron en sus propuestas artísticas. En la segunda mitad del siglo, desde la música, la vuelta a los orígenes vendría de la mano de Pierre Schaeffer, quien lo hizo con su propuesta de música concreta y las investigaciones del nuevo Solfeo. Pierre Shaeffer llega a la conclusión de que la música se origina de dos principios elementales que cualquier persona puede realizar, repetir un sonido y variarlo y todas las músicas del mundo están basadas en él.

En Francia la Pedagogía de Creación Musical tuvo un impulso extraordinario en los años setenta, reflejado en programas radiofónicos estatales como L'Oreille en Colimaçon y hoy en día forma parte de los currículos habituales de los escolares. Las investigaciones en este campo están abiertas hoy en día en Francia, Italia, España y Argentina en donde existen prácticas de esta pedagogía. Las jóvenes generaciones de artistas están aportando las nuevas tecnologías y el arte sonoro, con una frescura que es más oxígeno para esta forma de entender la pedagogía de la música y son además las fuentes de la actualización que debemos hacer de la PCM en todo momento.

La creación sonora es, ante todo, un descubrimiento para el concepto de música electroacústica. Para entender lo que estamos diciendo es importante conocer la apreciación que los músicos electroacústicos tienen de su trabajo como un factor a considerar. Varios compositores del GRM entre ello Josehp Baylle han comentado, en entrevistas publicadas por François Delalande en Las conductas musicales ${ }^{6}$ como viven el proceso de creación. De sus palabras se deduce que para ellos la generación de una obra implica un proceso en el que la materia se muestra al creador, como si la creación sonora fuera un hallazgo, un descubrimiento y en alguna medida algo externo a la decisión del músico. Llorenç Barber habla también de algo similar al decir que la música está en las cosas y que solo habría que despertarla. Nuestros procesos de creación y nuestra propia experiencia están de acuerdo con ambos sentimientos, tanto cuando nos enfrascamos en una obra electroacústica, como cuando realizamos una propuesta concreta. Estas opiniones están muy alejadas de las que tiene un compositor de pentagrama, lo que nos habla de que la composición, hoy en día, es una realidad, o realidades, diferentes de lo que se entendía por tal. Por ello, preferimos hablar en muchas ocasiones de creación sonora y no de composición musical, aunque al final es muy difícil no mezclar ambos términos.

Pareciera que la generación de una obra, sobre todo en el caso de la obra electroacústica, estuviera más acorde con la manera de trabajar de un científico, que descubre por azar, algo imprevisto pero fantástico en su tarea cotidiana de investigación, que con la

\footnotetext{
6 Libro publicado en Italia por los servicios de publicación de la universidad de Bolonia, ver bibliografía. Actualmente está en vías de publicación la traducción en español de Terencia Silva Rojas e Inmaculada Cárdenas.
} 
de un compositor tradicional que conoce las reglas de composición previamente y donde el resultado dependerá de la finura en la utilización de estas. Muy diferente es la forma en la que el electroacústico se relaciona con el sonido. Componer es para este, en primer lugar, buscar materiales sonoros interesantes, con los que construirá lo se ha dado en llamar "objeto sonoro". Estos objetos sonoros nacen de la manipulación manual de los materiales o cuerpos sonoros incluidos los instrumentos de música. Todas las manipulaciones posibles son grabadas, $\mathrm{y}$ posteriormente trabajadas con programas de síntesis y edición del sonido. Las modificaciones obtenidas de estas manipulaciones electrónicas formaran parte del material de composición de la obra o de archivos sonoros que el músico puede recuperar en otras propuestas. Reunido el material que el músico estima suficiente, la creación electroacústica entraría en la fase de montaje o maquetado, para ulteriormente pulir el trabajo con el filtraje y la ecualización hasta considerarse acabado. En resumen este sería el recorrido mínimo y habitual de trabajo de un músico electroacústico.

Traspasar este esquema a la escuela no requiere mayor trabajo que la información necesaria del maestro sobre la música electroacústica y sus métodos de trabajo más habituales. Buscar materiales sonoros interesantes, es algo que los niños hacen habitualmente y más, si son incitados por su profesor en la búsqueda, generando de esta forma un ambiente distendido y espontáneo en el que la música va a surgir del juego sonoro.

Desde el año 96 el GCMUS ha sido el laboratorio de estas prácticas sonoras a través de los trabajos de creación y divulgación del grupo. Este grupo nace apoyado por la vicerrectoría de cultura del campus de Lugo pero muy vinculado a la Escuela de Formación del Profesorado. Durante una década el GCMUS ha organizado desde el vicerrectorado de cultura, con créditos de libre configuración cursos extensos. Estos cursos, de canto contemporáneo conducidos por Mónica Álvarez, miembro fundador del GCMUS y de electrónica musical conducidos por Arturo Vaquero, miembro del GCMUS desde el año 1998, han desarrollado en sus propuestas de creación los parámetros de la PCM. De noviembre a mayo, durante dos horas semanales los alumnos han sido formados en canto y en electrónica musical. Cada curso ha estado dedicado a un tema y a un artista significativo para los planteamientos de la PCM. Son clarificadores los títulos y los artistas a los que se les han dedicado. Citamos algunos a modo de ejemplo: música e comics, música e transporte, música $e$ palabra, música e espazos, música e cidade o música e natureza dedicados a Pierre Schaeffer, a François Delalande, a José Iges y Concha Jerez, al Trio Flatus Vocis, a Llorenç Barber o José Luís Carles. Este formato de curso nos permitía trabajar las técnicas propias de la voz o de la electrónica musical y realizar propuestas creativas que han sido estrenadas en los conciertos de primavera del GCMUS. EL sociólogo francés Michel Imberty deja claro en su pensamiento que la música tiene dos orígenes posibles en el hombre, uno el canto y otro la música instrumental. En las propuestas de creación que hemos desarrollado desde el GCMUS ambos elementos, claves en la aplicación de la PCM han sido ejes de estas.

Cantar es algo muy íntimo para el ser humano $y$ hacerlo en grupo es muy gratificante. Si extendemos el uso de la voz al manejo de otras técnicas vocales, al canto difónico, y sencillamente inventamos con la voz formas de expresión nuevas, tenemos un abanico infinito de posibilidades para trabajar la creación sonora vocal en la escuela. La voz nos permite hacer no solo sonidos, sino también ruidos con los que recrear entornos sonoros en imitaciones múltiples de la realidad cotidiana o inventar nuevas realidades sonoras.

El trabajo de creación por ordenador, requiere obligadamente el aprendizaje de la técnica y el manejo de los programas, pero las etapas a proseguir en la realización de una obra son en esencia similares a las de la creación vocal: la búsqueda del sonido y la realización de las grabaciones sonoras, el trabajo se diferencia a partir de aquí. La educación sonora a través del ordenador sigue teniendo la educación de la escucha como base, y a través de ella los 
alumnos aprenden a apreciar y valorar sonidos y ruidos cotidianos y del entorno.

Este aspecto novedoso nos lleva al concepto de paisaje sonoro. El paisaje sonoro, además de ser una forma de creación, puede ser también una herramienta de trabajo educativo, el estudio sonoro del entorno. Propuestas encaminadas al cuidado ecológico de nuestro mundo sonoro, con las posibilidades de recuperar y preservar patrimonios sonoros que están desapareciendo, o recrear entornos sonoros con instrumentos o por ordenador para generar paisajes sonoros son algunas de las formas que podemos trabajar. Dentro del trabajo de recuperación de entornos sonoros en peligro está la propuesta de Juan Gil López y los artistas de "escoitar.org. En el master DAEN, se ha realizado el primer trabajo de investigación con la creación de un mapa sonoro de Lugo por Abraham Felpeto en la materia Música e Natureza, disponible en la Web. Otro artista pedagogo que trabaja este tema es el paisajista sonoro José Luis Carles desde su programa en Radio Clásica "La casa del sonido" al que hemos sido invitados en varias ocasiones ${ }^{7}$. Es importante no olvidar que para los paisajistas sonoros los entornos, no solamente hacen referencia a los entornos naturales, sino que están abiertos a los entornos urbanos e industriales. En muchos de los trabajos publicados del GCMUS se ha trabajado este concepto de paisaje sonoro, pues descubrir la música de los entornos es en suma la esencia de lo que decimos. El último CD editado del GCMUS Música, Espazos e Cidade recoge una muestra amplia de este proceder con obras del GCMUS y de artistas invitados a los Sons Creativos.

Las propuestas contemporáneas del arte sonoro nos permiten situar al alumno a) como protagonista del hacer sonoro y b) al mismo tiempo como un elemento del entorno sonoro. La música está en las cosas, solo hay que despertarla, podemos decirlo de otra manera: no estamos fuera del paisaje formamos parte del mismo. En la primera situación educativa tendremos de nuestro lado todas las propuestas de la música concreta, de la música electroacústica, además de las infinitas propuestas del arte sonoro. Conocer estas experiencias sonoras es una fuente inagotable de ideas para desarrollar en el aula. El desarrollo de nuevos conceptos como el de paisaje sonoro de Murray Shafer con sus soundscape nos permiten formar parte del paisaje, vivirlo $y$ recrearlo en propuestas en las que los entornos sonoros nos hablan de una escucha diferente de estos, y nos proponen lecturas diversas del cotidiano. Una vez más la tecnología está de nuestro lado y la grabadora sigue siendo la herramienta principal de trabajo.

Hoy en día la tecnología forma parte de nuestro cotidiano y debemos entenderla como una aliada. Así lo hacen los artistas y los museos, y las galerías de arte están llenas de obras que rompen las fronteras, que involucran al público en la obra, o lo hacen formar parte de ella, pero sobre todo lo incitan a leer el mundo de otras maneras, como también lo incitan a nuevos comportamientos, a cambiar o respetar los entornos, con esta nueva relación del individuo o del grupo con las obras de arte. Terminará siendo cierta la propuesta dadaísta de "arte para todos", o su nueva mutación que podríamos enunciar como "arte con todos y entre todos". El artista, el músico no necesita hoy en día de grandes inversiones económicas para disponer de lo necesario para hacer música, lo que además está no solo multiplicando exponencialmente las propuestas, sino las posibilidades de darlas a conocer en los foros habituales de You Tube y Face Book.

El GCMUS ha cambiado recientemente su nombre por el de GCSUS Grupo de Creación Sonora para adecuarse a los retos más recientes del arte sonoro y con este nombre ha publicado el último trabajo del grupo Música, Espazos e Cidade. Con este son cinco trabajos publicados en sus años de vida: Los CDs Música e arquitectura y La ópera Serea $e$ o contador de contos, El DVD O Grupo de Creación Musical en Concerto, el CD Música e entorno y el DVD Música, espazos e cidade citado. Algunos de estos trabajos están reeditados en el net label alg-a.

Ver bibliografía y webs recomendadas. 
Estas obras se han programado en foros nacionales $e$ internacionales de prestigio: en ciudades americanas como New York, La Habana, México o Lima; en ciudades europeas como París, Bourges y Bolonia, en España en ciudades como Madrid, Barcelona, Valencia, Palma de Mallorca, Santander, Alicante, Valladolid, Palencia, Cuenca, Cádiz, Santiago y Lugo. Se han escuchado en centros de importancia como el Reina Sofía, en la SGAE en el Festival electroacústico Punto de Encuentro, en el Festival electroacústico de Synthrse, el Festival Internacional de Música de la Habana, el Festival de Teatro de Cádiz, en la Programación de la Fundación ACA en Palma, y en los conciertos del GCMUS y en los Sons Creativos.

Vamos a terminar escuchando dos ejemplos de los trabajos realizados por el GCMUS con la colaboración de sus miembros y alumnos de los cursos del GCMUS. El primero es el tercer movimiento de la Suite electroacústica: Mosteiro Suite, obra electroacústica que me gusta definir como electroacústica desnuda. Realizada en el monasterio de Sobrado dos Monxes, es un estudio de las acústicas del lugar. Para ello trabajamos separadamente con un violonchelista, con un dúo de voces masculinas y un bombardino. Todos los instrumentistas estuvieron invitados a jugar con diferentes técnicas en los espacios del monasterio y bajo algunas reglas que previamente les indiqué. Nunca tocaron juntos. Esta obra está integrada en el CD Música y arquitectura y ha sido estudiada por Clara Ramhallo en su tesis doctoral Arquitectura diálogos com a música, leída en la Escuela de Arquitectura en 2008 en el departamento de Historia, Teoría y Composición de Sevilla. Ha sido reeditada en el net label alg-a Música y arquitectura.

La segunda obra es A morte do dansak. Cuento radiofónico inspirada en el cuento "La muerte de Rasu-ñiti" del antropólogo y escritor indigenista José María Arguedas. Arguedas escribió en castellano el pensamiento mágico de los indios para enseñar a los criollos la otra parte del Perú. En 2011 esta obra se estrenaba en Lima en la Universidad Antonio Ruiz de Montoya en la inauguración del curso académico y en esta ocasión fue bailada por dos bailarines de tijeras. Cuento radiofónico en el que recuperé vivencias infantiles de los años 50. Obra electroacústica para cinta, coro y actores y narradora, se estrenó en Lugo en 2007 en los conciertos de primavera del GCMUS. Un trabajo de investigación sobre Arguedas y los danzarines de tijeras fue necesario. La parte instrumental se construye con instrumentos tradicionales propios de la música de los dansaks, arpa diatónica y violines manipulados por ordenador. Con formato operístico, en su desarrollo se mezcla lo lírico con lo hablado en una tensión dramática que refleja la muerte como preludio de la vida. Un artículo sobre esta obra está publicado en América, Américas en la colección Thema en 2009. Escucharemos solo un fragmento pues su duración completa es de veinte minutos. Esta obra ha sido reeditada en el net label alg-a Música e entorno.

No quiero terminar sin mencionar: A mis padres que me enseñaron el valor del estudio. A mis profesores, amigos y compañeros que estuvieron ahí cuando los necesité. A los directores de este centro, a su decano, a los vicerrectores de coordinación del campus de Lugo y a los vicerrectores de cultura que siempre apoyaron y apoyan mis iniciativas, así como a las personas del vicerrectorado de cultura cuya ayuda fue en muchos casos inestimable. Al Grupo de Teatro de la universidad quienes gustosos participaron cuando les pedí, Al Espacio de Danza Universitario con quienes realicé algunas de las obras más queridas. A los miembros del GCSUS recientemente incorporados Efraím Díaz y Jesús Otero-Yglesias. Y a mi compañera Terencia Silva correctora de textos y creadora de muchos de ellos como el libreto de la opera Serea e o Contador de Contos inspirada en Torrente Ballester.

Gracias a todos por su atención. 